\title{
Imaging characteristics of H3 K27M histone-mutant diffuse midline glioma in teenagers and adults
}

\author{
Stefanie Thust ${ }^{1,2}$, Caroline Micallef ${ }^{1,2}$, Sachi Okuchi ${ }^{1,2}$, Sebastian Brandner $^{3}$, Atul Kumar ${ }^{3}$, \\ Kshitij Mankad $^{4}$, Stephen Wastling ${ }^{1,2}$, Laura Mancini ${ }^{1,2}$, Hans Rolf Jäger ${ }^{1,2}$, Ananth Shankar ${ }^{5}$ \\ ${ }^{1}$ Neuroradiological Academic Unit, Department of Brain Repair and Rehabilitation, UCL Institute of Neurology, London, UK; ${ }^{2}$ Lysholm \\ Department of Neuroradiology, The National Hospital for Neurology and Neurosurgery, University College London Hospitals NHS Foundation \\ Trust, London, UK; ${ }^{3}$ Department of Neurodegenerative Disease, UCL Queen Square Institute of Neurology and Division of Neuropathology, The \\ National Hospital for Neurology and Neurosurgery, University College London NHS Foundation Trust, London, UK; ${ }^{4}$ Department of Radiology, \\ Great Ormond Street Hospital for Children, London, UK; ${ }^{5}$ Teenage and Young Persons' Cancer Unit, Department of Paediatric Oncology, \\ University College London Hospitals NHS Foundation Trust, London, UK
}

Correspondence to: Stefanie Thust, MD, FRCR. Consultant Neuroradiologist, Honorary Associate Professor, National Hospital for Neurology and Neurosurgery, Queen Square, London WC1N 3BG, UK. Email: s.thust@ucl.ac.uk.

Background: To assess anatomical and quantitative diffusion-weighted MR imaging features in a recently classified lethal neoplasm, H3 K27M histone-mutant diffuse midline glioma [World Health Organization (WHO) IV].

Methods: Fifteen untreated gliomas in teenagers and adults (median age 19, range, 14-64) with confirmed H3 K27M histone-mutant genotype were analysed at a national referral centre. Morphological characteristics including tumour epicentre(s), T2/FLAIR and Gadolinium enhancement patterns, calcification, haemorrhage and cyst formation were recorded. Multiple apparent diffusion coefficient $\left(\mathrm{ADC}_{\mathrm{min}}\right.$, $\mathrm{ADC}_{\text {mean }}$ ) regions of interest were sited in solid tumour and normal appearing white matter $\left(\mathrm{ADC}_{\mathrm{NAWM}}\right)$ using post-processing software (Olea Sphere v2.3, Olea Medical). ADC histogram data $\left(2^{\text {nd }}, 5^{\text {th }}, 10^{\text {th }}\right.$ percentile, median, mean, kurtosis, skewness) were calculated from volumetric tumour segmentations and tested against the regions of interest (ROI) data (Wilcoxon signed rank test).

Results: The median interval from imaging to tissue diagnosis was 9 (range, 0-74) days. The structural MR imaging findings varied between individuals and within tumours, often featuring signal heterogeneity on all MR sequences. All gliomas demonstrated contact with the brain midline, and $67 \%$ exhibited rimenhancing necrosis. The mean $\mathrm{ROI} \mathrm{ADC}_{\min }$ value was $0.84( \pm 0.15$ standard deviation, $\mathrm{SD}) \times 10^{-3} \mathrm{~mm}^{2} / \mathrm{s}$. In the largest tumour cross-section (excluding necrosis), an average $\mathrm{ADC}_{\text {mean }}$ value of $1.12( \pm 0.25) \times 10^{-3} \mathrm{~mm}^{2} / \mathrm{s}$ was observed. The mean $\mathrm{ADC}_{\min / \mathrm{NAWM}}$ ratio was $1.097( \pm 0.149)$, and the mean $\mathrm{ADC}_{\text {mean/NAWM }}$ ratio measured $1.466( \pm 0.299)$. With the exception of the $2^{\text {nd }}$ centile, no statistical difference was observed between the regional and histogram derived $\mathrm{ADC}$ results.

Conclusions: H3 K27M-mutant gliomas demonstrate variable morphology and diffusivity, commonly featuring moderately low ADC values in solid tumour. Regional ADC measurements appeared representative of volumetric histogram data in this study.

Keywords: Glioma; histones; diffusion magnetic resonance imaging

Submitted Nov 15, 2019. Accepted for publication Jul 07, 2020.

doi: 10.21037/qims-19-954

View this article at: http://dx.doi.org/10.21037/qims-19-954 


\section{Introduction}

Diffuse midline gliomas are brain tumours with a mean survival of approximately 9 months from diagnosis $(1,2)$. Midline gliomas may arise anywhere near the cerebral or infratentorial brain midline and occasionally develop in the spinal cord $(3,4)$. They demonstrate overlapping anatomical features with the now discontinued World Health Organization (WHO) category of diffuse intrinsic pontine glioma (DIPG) (5).

In 2012, aberrations in a regulatory histone gene (H3) resulting in an amino acid substitution from lysine to methionine (K27M) were discovered in up to $40 \%$ of paediatric glioblastomas $(6,7)$. H3 K27M mutations have since been identified as a key genetic trait of midline gliomas, present in up to $80 \%$ of childhood DIPG cases and associated with a dismal prognosis (mean survival 0.73 years) compared to midline gliomas lacking a histone mutation (mean survival 4.6 years) $(2,8)$. Although H3 K27M-mutant gliomas tend to manifest at a much younger age (median 10.5, range, 5-23 years) (3) than conventional glioblastoma, they also develop in adults across a wide age spectrum with exceptionally poor survival (9-11).

Histones are nuclear protein complexes, which condense and structure chromosomal DNA into functional units with the potential to modify gene activity (12). Histone octamers, consisting of paired $\mathrm{H} 2 \mathrm{~A}, \mathrm{H} 2 \mathrm{~B}, \mathrm{H} 3$, and $\mathrm{H} 4$ subunits, contain terminal protein terminals as the access point for post-translational modification (6). It has been hypothesised that the genetic code and spatial orientation of these histone terminals direct epigenetic processes, including DNA repair and cell proliferation. Because sixteen nearly identical genes encode histone $\mathrm{H} 3$, it is incompletely understood how mutations in a single $\mathrm{H} 3$ gene produce tumour growth (13). The transcriptomic profile of $\mathrm{H} 3 \mathrm{~K} 27 \mathrm{M}$ resembles mid to late fetal stages of thalamic and corpus striatum development, which could explain the associated tumour locations (3). Consistent with the genetic signature of childhood glioblastoma, adult histone-mutant gliomas are isocitrate dehydrogenase (IDH) wild-type, but may exhibit loss of alpha-thalassaemia-retardation-X (ATRX) gene expression and chromosome 10q loss (14). H3 K27M-mutant gliomas in most cases display histological features of glioblastoma, or progress rapidly if discovered in the low grade stage. A distinct entity 'diffuse midline glioma, H3 K27M-mutant, WHO grade IV' has been newly adopted into the latest $2016 \mathrm{WHO}$ Classification of Central
Nervous System (CNS) Tumours, thereby replacing the previous (DIPG) nomenclature (15). Imaging is essential in the investigation of $\mathrm{H} 3 \mathrm{~K} 27 \mathrm{M}$-mutant gliomas to estimate the tumour extent, and because the diagnosis may be considered based on lesion site. The deep location within eloquent structures poses a risk to biopsy, in a situation where a rapid diagnosis is required. Midline gliomas may present with obstructive hydrocephalus and critical mass effect (16), particularly if enclosed in the infratentorial compartment. To date, no distinctive structural imaging feature has been identified for histone-mutant gliomas (17). Several MR imaging descriptions exist for DIPG prior to the integrated 2016 WHO diagnosis; it is likely that a substantial proportion of this literature applies to $\mathrm{H} 3$ K27M-mutant glioma, but few imaging reviews address the new entity specifically (18). Reduced diffusivity is a well-known feature of cellular gliomas (19) and has been observed as a poor prognostic predictor in DIPG (20). We aimed to analyse morphological and diffusion-weighted imaging data in genotypically confirmed H3 K27M-mutant gliomas, derived from preoperative clinical studies.

\section{Methods}

\section{Patient cobort}

Institutional ethics approval was obtained, with informed consent waived due to the nature of the disease and retrospective analysis.

Since the classification of H3 K27M histone-mutant glioma (15), 15 individuals aged 14-64 years (median 19 years, 9 female) with a proven diagnosis were treated at our specialist brain tumour unit (between 2016 and 2019). In all cases, MR imaging acquired prior to tissue diagnosis and treatment was analysed.

\section{Histopathology and molecular analysis}

All tissues were fixed in formalin for at least 4 hours, followed by processing through graded alcohols and xylene, to paraffin according to standard practice in histology laboratories; $4 \mu \mathrm{m}$ thick sections of the formalin fixed paraffin embedded samples were mounted on glass slides. All samples were examined initially on haematoxylin and eosin stained sections, followed by immunostaining according to routine diagnostic protocols, including antibodies against IDH1 (R132H), H3 K27M, and ATRX, and Ki67 on a Roche Ventana benchmark platform (21-23). 


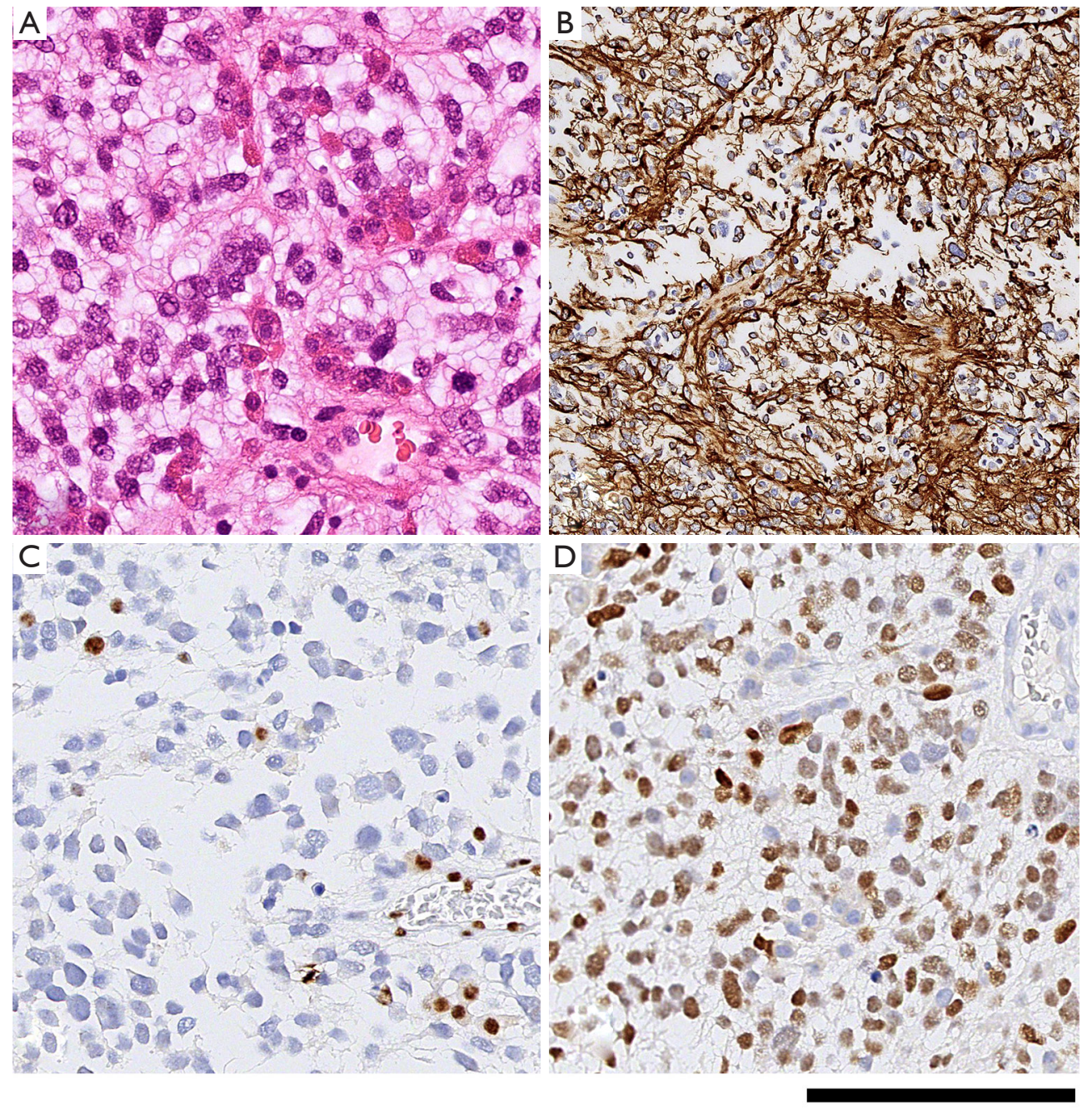

Figure 1 Histological and immunohistochemical features of histone H3 K27M mutant midline glioma (case 15). (A) Tinctorial stain with haematoxylin and eosin shows a moderately cellular glial tumour with relatively monomorphic nuclei. (B) immunohistochemical staining for glial fibrillary acidic protein (GFAP) shows labelling of most tumour cells which are arranged along glial fascicles. (C) Loss of expression of the ATRX protein: brown stained nuclei indicate residual (local) cells with retained ATRX expression whilst tumour cells (blue counterstain) have lost ATRX expression. (D) Immunostaining for mutant histone H3 K27M. The antibody detects the mutant protein only, thus labels all nuclei of tumour cells but not of vascular cells or local glial cells. Scale bar corresponds to $180 \mu \mathrm{m}$ in (A,C,D) and $360 \mu \mathrm{m}$ in (B).

Molecular analysis was carried out to confirm the histone mutation according to published protocols (24). All tissue samples fulfilled the histological and molecular criteria for diffuse midline glioma, H3 K27M-mutant (WHO IV). A histopathology imaging example is shown in Figure 1.

\section{MR imaging data}

Because our institution represents a quaternary referral centre, the MR imaging studies were performed on several
1.5T $(\mathrm{n}=10)$ and $3 \mathrm{~T}(\mathrm{n}=5)$ systems, consisting of $\mathrm{T} 2$ weighted $(\mathrm{T} 2 \mathrm{w})$, fluid-attenuation inversion recovery (FLAIR), pre- and post-gadolinium T1-weighted (T1w), $+/-\mathrm{T} 2 * /$ susceptibility-weighted (SWI) sequences, and 3-directional diffusion-weighted MRI (DWI) with two b values of $0-1,000 \mathrm{~mm}^{2} / \mathrm{s}$, and in some cases an additional b500 $\mathrm{mm}^{2} / \mathrm{s}$ value under the presumption that adding an intermediate image at exactly half the highest b-value will not change the calculated apparent diffusion coefficient (ADC) (25). The conventional imaging parameters were 
as follows: T2w (TR/TE, 3,000-6,270/80-380 ms; FOV, 179-231 mm × 220-287 mm; slice thickness, 1-6 mm; matrix, 256-512 × 226-532), FLAIR (TR/TE, 6,00011,000/81-363 ms; TI, 2,370-2,800 ms; FOV, 193-240 mm × 239-298 mm; slice thickness, 1-6 mm; matrix, 256-328 × 151-241), pre and post contrast-enhanced T1w (TR/TE, 5.25-2,020/1.65-15 ms; FOV, 193-280 × 240-348 mm; slice thickness, 0.9-6 mm; matrix, $256 \times 192-256), \mathrm{T} 2 *(\mathrm{TR} / \mathrm{TE}$, 788-857/16-26 ms; FOV, 195-230 mm × 42-286 mm; slice thickness, $5 \mathrm{~mm}$; matrix, 256-320 × 168-256), SWI (TR/ TE, 25-49/19-49 ms; FOV, 185-230 mm × 230-286 mm; slice thickness, 1.5-2 mm; matrix, 256-320 × 163-256), and DWI (TR/TE, 3,078-11,500/55-102 ms; FOV, 210 $240 \mathrm{~mm} \times 261-298 \mathrm{~mm}$; slice thickness, $2.5-6 \mathrm{~mm}$; matrix, 84-192 × 84-192).

\section{ADC quantification}

ADC maps were calculated using clinically integrated postprocessing software (Olea Sphere v2.3, Olea Medical). Two board certified neuroradiologists with subspecialisation in neuro-oncology (ST 5-year experience and CM 10-year experience) in consensus placed $\mathrm{ADC}$ regions of interest (ROIs) according to published methods (26-28); three small (30-40 $\left.\mathrm{mm}^{2}\right)$ ROIs were sited in the visually perceived lowest ADC portions of each H3 K27M-mutant glioma on one or more image slices. The mean value of the lowest $\mathrm{ADC}$ measurement was designated the minimum $\mathrm{ADC}$ value $\left(\mathrm{ADC}_{\min }\right)(28)$. One ROI $\left(\mathrm{ADC}_{\text {mean }}\right)$ was then placed to cover most of the largest axial tumour crosssection as reported in (27), taking care to exclude necrosis, macroscopic haemorrhage and lesion margins. For comparison, an additional ROI was placed into normal appearing centrum semiovale white matter $\left(\mathrm{ADC}_{\mathrm{NAWM}}\right)$. Absolute $\mathrm{ADC}$ values, as well as $\mathrm{ADC}_{\min / \mathrm{NAWM}}$ and $\mathrm{ADC}_{\text {mean/NAWM }}$ ratios were calculated blinded to published thresholds (29) and at an interval to ROI siting to minimise bias. Subsequently, volumetric segmentations (excluding macroscopic necrosis) were completed for each whole tumour in order to produce ADC histogram data. For this, volumes of interest (VOIs) were drawn onto the b0 images in Olea Sphere v2.3 with an automated VOI copy generated on the ADC map. From the ADC volume, a cumulative ADC histogram was generated for each glioma. Statistical testing (Wilcoxon signed rank test for related samples) was performed in SPSS 25 (IBM, New York) to assess for differences between the ROI and VOI histogram derived $\mathrm{ADC}$ values.

\section{Visual rating}

Tumour location was specified according to the predominant site(s) of expanded tissue abnormality. A T2w-based manual segmentation of each whole lesion was performed to measure tumour volumes. T2w/FLAIR signal characteristics were described, whereby the ability to draw around the lesion on T2w/FLAIR was designated as distinct margin and uncertainty regarding lesion borders as indistinct. Haemorrhage was assessed by inspecting non-contrast $\mathrm{T} 1 \mathrm{w}$ and $\mathrm{T} 2 \mathrm{w}$. CT, T2* and/or SWI were taken into consideration, where available. Enhancement patterns were classified as non-enhancing, solid or rimenhancing. Rim-enhancement surrounding central necrosis was distinguished from cysts, defined as central fluid signal isointense to CSF with absent or minimal contrast uptake. If hydrocephalus was present, it was documented if this was severe enough to require shunting.

\section{Results}

\section{Clinical findings}

Symptoms of raised intracranial pressure, motor deficits, and seizures, alone or in combination, were the most frequent clinical manifestations identified in the patient group. Other signs included acute onset squint, double vision, swallowing difficulties slurred speech and abnormal gait. Behavioural and mental changes were common in individuals with thalamic tumours. Several patients showed signs of cognitive dysfunction (i.e., language, attention, executive functioning), with deterioration of handwriting and/or speech. Overall, the presenting clinical features appeared predominantly dependent on tumour location, without any H3 K27M-specific symptomatology.

\section{ADC quantification}

The median interval between the imaging and tissue diagnosis was 9 days (range, 0-74 days). Table 1 shows the ADC values obtained in 15 gliomas. The solid tumour ROI $\mathrm{ADC}_{\text {min }}$ results measured a mean of $0.84\left( \pm 0.15\right.$ standard deviation, SD) $\times 10^{-3} \mathrm{~mm}^{2} / \mathrm{s}$. The solid tumour ROI $\mathrm{ADC}_{\text {mean }}$ values within the largest crosssection had a mean of $1.12( \pm 0.25) \times 10^{-3} \mathrm{~mm}^{2} / \mathrm{s}$. A mean of $0.76( \pm 0.06) \times 10^{-3} \mathrm{~mm}^{2} / \mathrm{s}$ was observed for the $\mathrm{ADC}_{\mathrm{NAWM}}$ values. The $\mathrm{ROI} \mathrm{ADC}_{\min / \mathrm{NAWM}}$ ratio values measured a mean of $1.097( \pm 0.149)$, and for the ROI $\mathrm{ADC}_{\text {mean/NAWM }}$ ratio the mean was $1.466( \pm 0.299)$. Table 2 shows the 
Table $1 \mathrm{ADC}$ (region of interest derived) measurements in $\mathrm{H} 3 \mathrm{~K} 27 \mathrm{M}$ histone-mutant glioma (ADC values displayed as $\times 10^{-3} \mathrm{~mm}^{2} / \mathrm{s}$ )

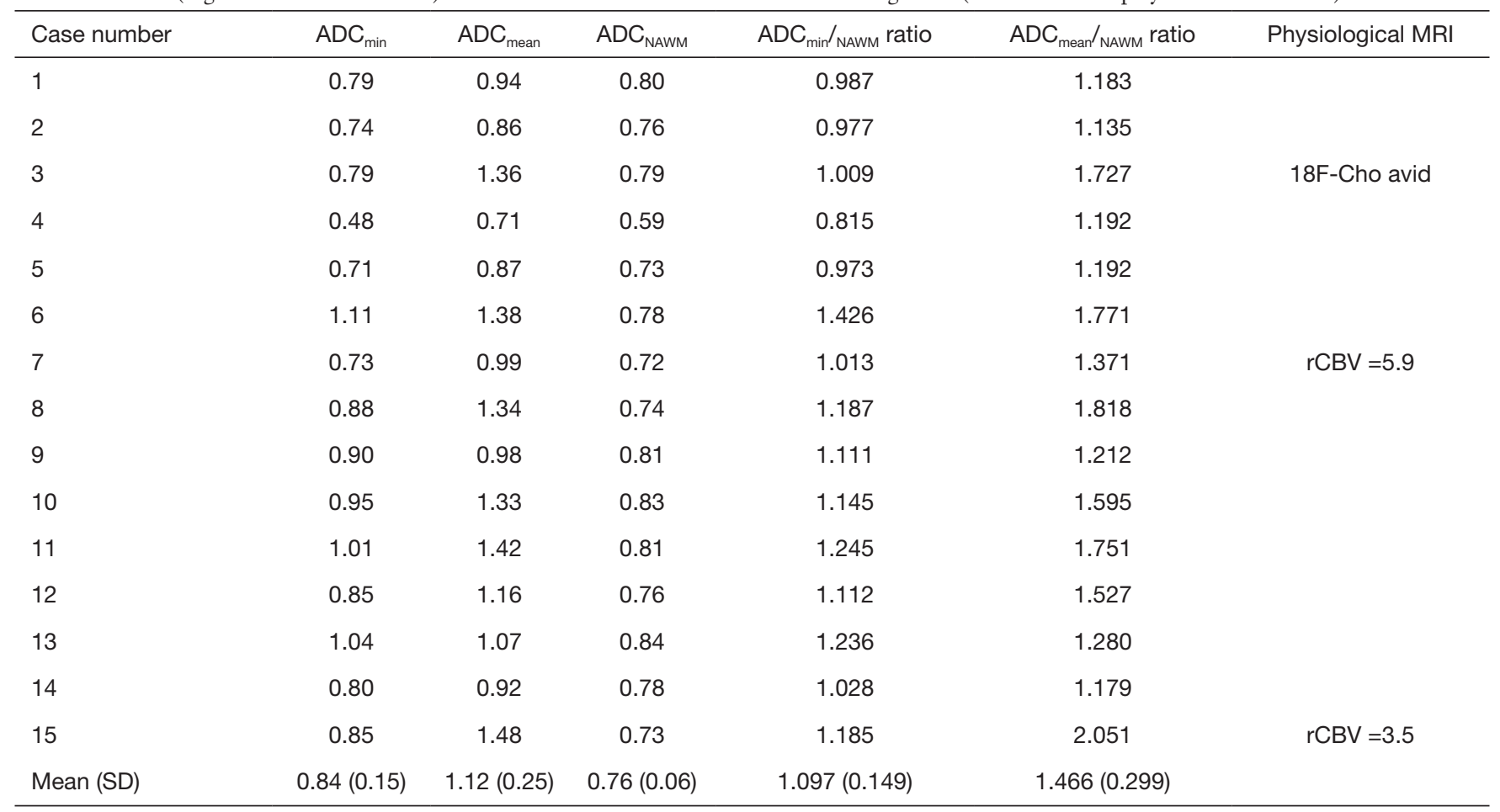

ADC, apparent diffusion coefficient; SD, standard deviation.

Table 2 ADC histogram data derived from tumour volumetric segmentation in $\mathrm{H} 3 \mathrm{~K} 27 \mathrm{M}$ histone-mutant glioma (ADC values displayed as $\times 10^{-3} \mathrm{~mm}^{2} / \mathrm{s}$ )

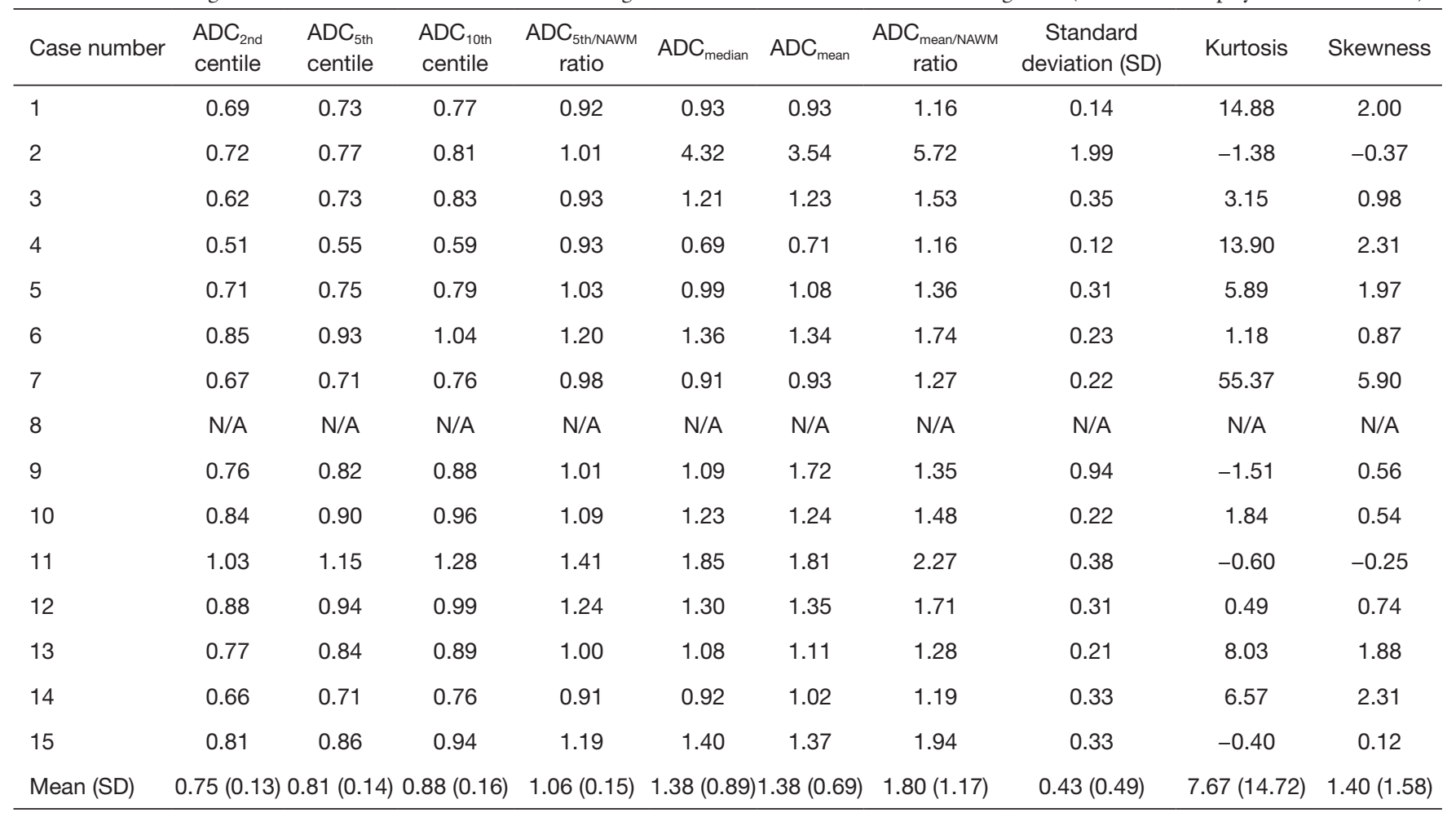

ADC, apparent diffusion coefficient; SD, standard deviation. 

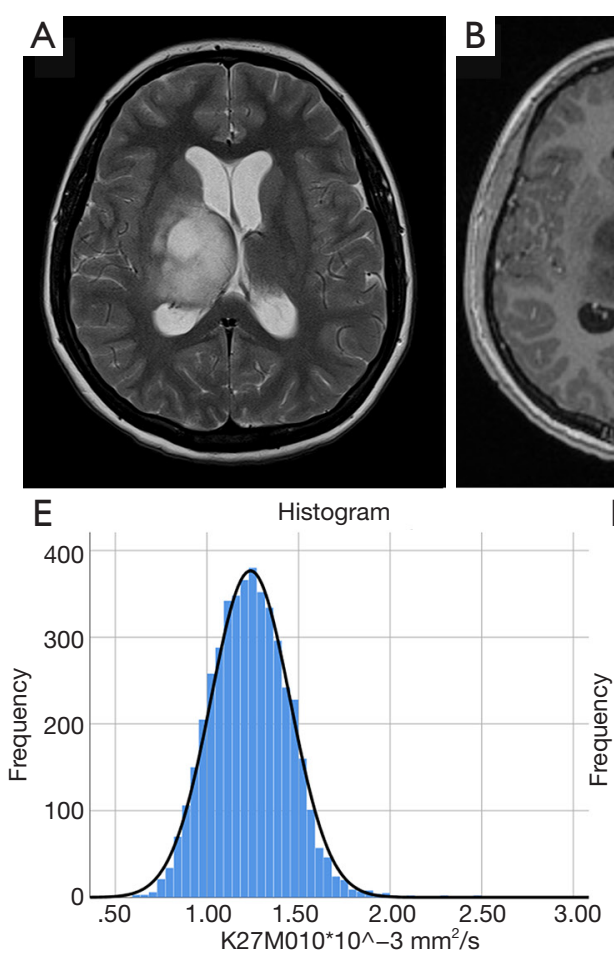

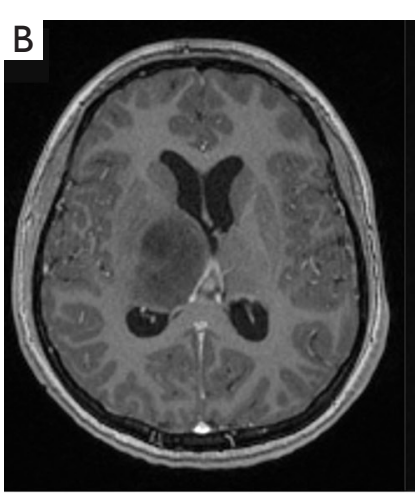

$\mathrm{F}$

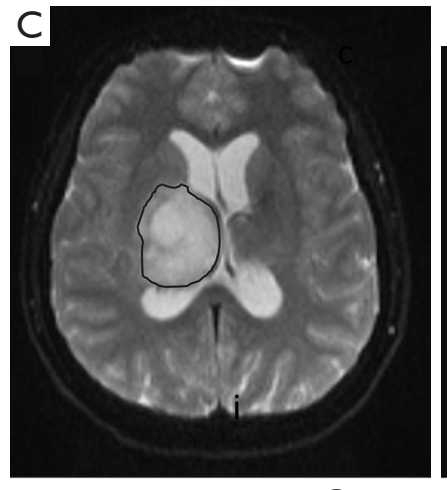

G

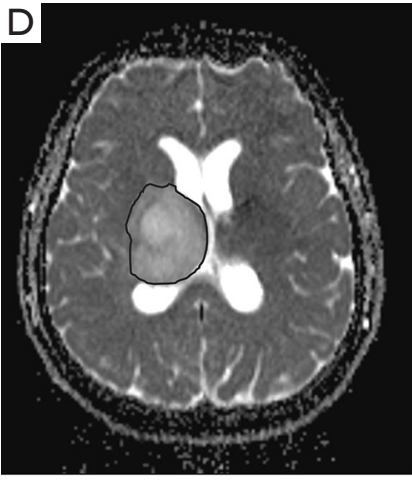

Histogram
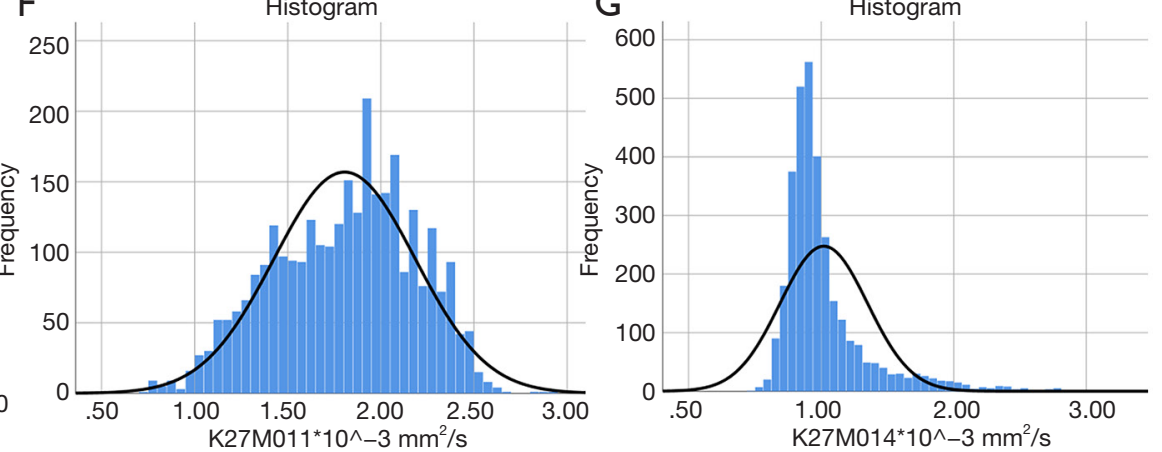

Figure 2 ADC histograms in H3 K27M histone-mutant glioma. T2w image (A), post gadolinium T1w image (B), b0 DWI image (C) and ADC map (D) demonstrating an example of glioma volumetric segmentation (case 10). Segmentations were performed on the b0 images under view of the corresponding anatomical sequences, then copied onto the ADC maps in Olea Sphere v2.3 (Olea Medical). Images (E,F,G) show ADC histograms in 3 different patients (case 10, case 11 and case 14). ADC, apparent diffusion coefficient.

results of the volumetric ADC histogram measurements. Figure 2 shows an example of different ADC histogram curves observed in the $\mathrm{H} 3 \mathrm{~K} 27 \mathrm{M}$ mutant glioma cohort. A biphasic ADC distribution was evident in 2 histograms, with one glioma (case 2) showing a high volumetric $\mathrm{ADC}_{\text {mean }}\left(3.54 \mathrm{~mm}^{2} / \mathrm{s}\right)$, likely due to inadvertent inclusion of necrotic tissue. In one glioma (case 8), no histogram could be produced due to missing data. A significant difference $(\mathrm{P}=0.01)$ was only observed between the $2^{\text {nd }}$ centile of the volumetric ADC histogram and the ROI $\mathrm{ADC}_{\text {min }}$ values. The comparisons between $\mathrm{ROI} \mathrm{ADC}_{\text {min }}$ and the $5^{\text {th }}$ and $10^{\text {th }}$ histogram percentiles showed no statistical difference $(\mathrm{P}=0.379$ and $\mathrm{P}=0.177$, respectively). No difference was observed between $\mathrm{ROI} \mathrm{ADC}_{\min / \mathrm{NAWM}}$ ratio and the $\mathrm{ADC}_{5 \text { th percentile/NAWM }}$ ratio measurements $(\mathrm{P}=0.421)$. The comparisons between $\mathrm{ROI} \mathrm{ADC}_{\text {mean }}$ and the histogram $\mathrm{ADC}_{\text {median }}$ and $\mathrm{ADC}_{\text {mean }}$ were non-significant $(\mathrm{P}=0.576$ and $\mathrm{P}=0.208)$. And no statistical difference was apparent between $\mathrm{ROI} \mathrm{ADC}_{\text {mean/NAWM }}$ ratio and the histogram $\mathrm{ADC}_{\text {mean } / \mathrm{NAWM}}$ ratio $(\mathrm{P}=0.60)$.

\section{Structural MRI features}

An overview of conventional imaging features is shown in Table 3. All H3 K27M-mutant gliomas were in contact with the brain midline (Figure 3). The lesion volumes ranged from 9.2 to $103.1 \mathrm{~cm}^{3}$. The definition of the noncontrast enhancing tumour margin appeared variable, whereby most lesions demonstrated heterogeneous T2/ FLAIR signal. The observed T2/FLAIR heterogeneity corresponded to visible differences in ADC signal, with facilitated diffusion shown in necrotic glioma components. None of the H3 K27M histone-mutant gliomas exhibited a T2-FLAIR mismatch sign. Several tumours contained haemorrhagic components (Figure 4), whereas calcification was not identified, and only two tumours contained cysts. Rim-enhancement surrounding necrosis was present in 10/15 (67\%) gliomas; 6/15 (40\%) patients required shunting for hydrocephalus. Two gliomas were imaged with dynamic susceptibility contrast enhanced (DSC) perfusion MRI (Figure 5), which revealed elevated relative cerebral blood volume (rCBV) indicative of neovascularity. 


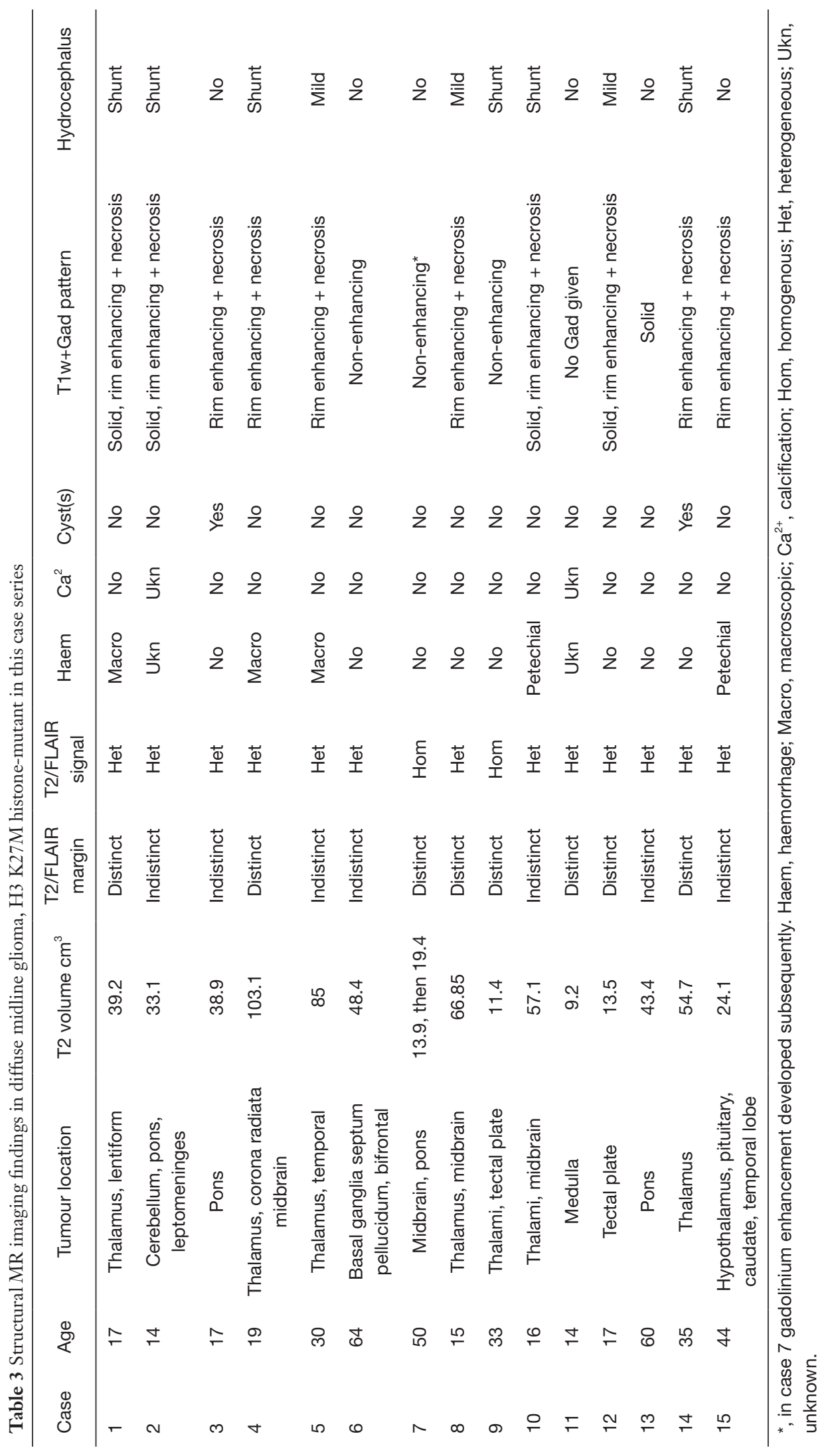



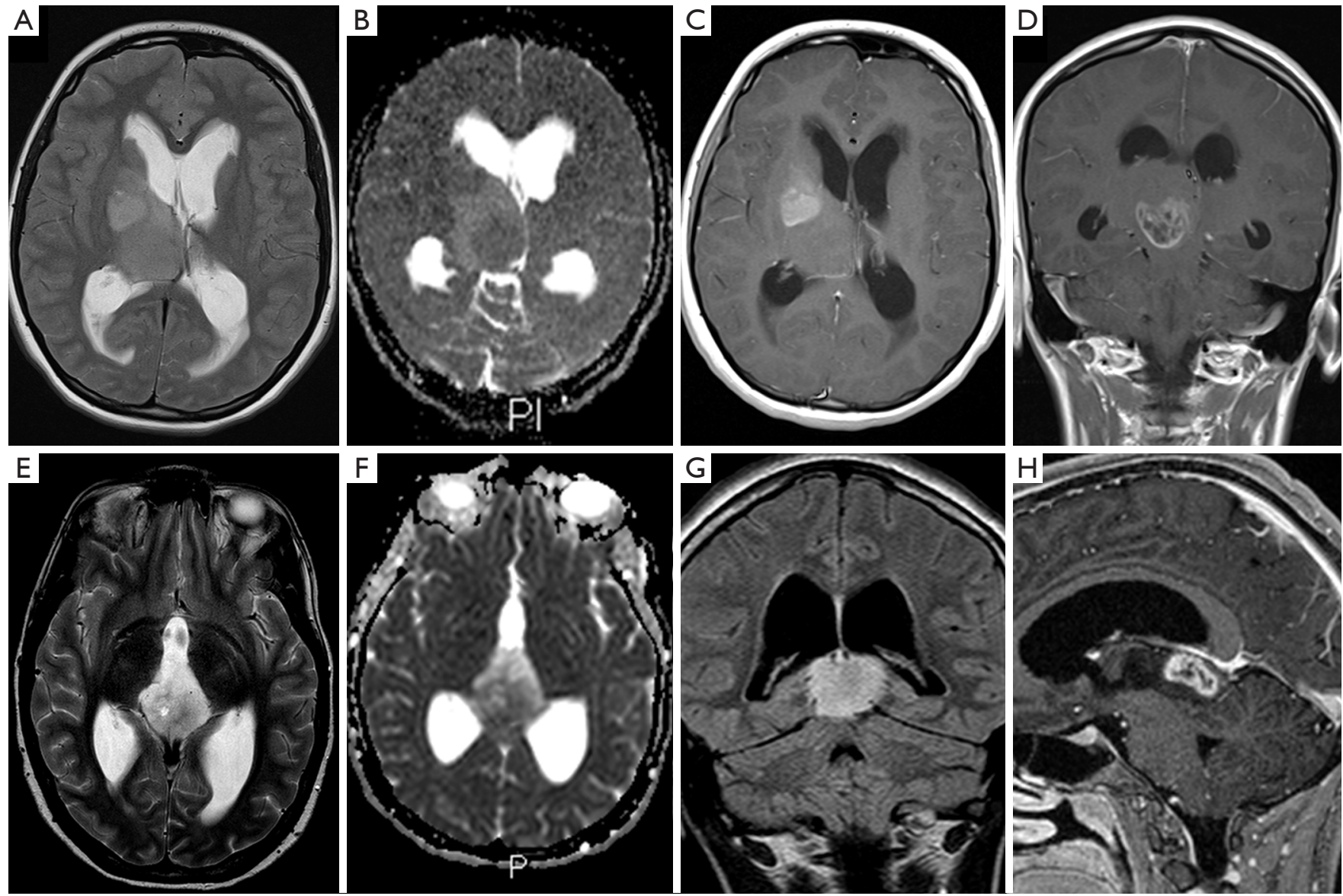

Figure 3 Locations of H3 K27M-mutant diffuse midline glioma. Case 1: T2w (A), ADC map (B), and post gadolinium T1w (C,D) images in a patient with a thalamic glioma. Case 12: T2w $(\mathrm{E}), \mathrm{ADC}$ map $(\mathrm{F})$, and post gadolinium T1w $(\mathrm{G}, \mathrm{H})$ demonstrating a tectal plate tumour epicentre. ADC, apparent diffusion coefficient.

In one case, ${ }^{18} \mathrm{~F}$-choline PET imaging was performed, showing radioactive tracer accumulation within enhancing tumour components (Figure 6).

\section{Discussion}

Few studies have investigated MR imaging findings in $\mathrm{H} 3$ K27M histone-mutant diffuse midline glioma, with most radiological series to date only describing qualitative tumour features $(18,30)$. We quantified ADC values in H3 K27Mmutant solid tumour components, and found diffusivity to be variable, characterised by a relatively narrow spectrum of $\mathrm{ADC}_{\text {min }}$ values.

Limited extracellular diffusion is recognised as a hallmark feature of cancer, presumed to indirectly reflect tissue cellularity (31). Low diffusivity has been reported in glioblastoma $(19,32)$, in WHO grade II/III malignant gliomas (33) and as an adverse prognostic biomarker in DIPG (20).

The $\mathrm{ADC}_{\text {min }}$ and $\mathrm{ADC}_{\text {mean }}$ values in our H3 K27Mmutant glioma cohort are consistent with previous findings in glioblastoma (34). Many of the tumour $\mathrm{ADC}_{\min }$ values were similar to normal appearing white matter (average $\mathrm{ADC}_{\mathrm{min} / \mathrm{NAWM}}$ ratio 1.097), which is in agreement with published data on ADC quantification in malignant gliomas $(28,35)$. During their research into the conventional imaging morphology of histone-mutant gliomas, Aboian et al. observed reduced diffusion (unquantified) on inspection (18), whereas in a recent larger $(\mathrm{n}=66)$ series no restricted diffusion was reported (30). H3 K27Mmutant gliomas reportedly have higher cell densities and pronounced nuclear pleomorphism compared to 

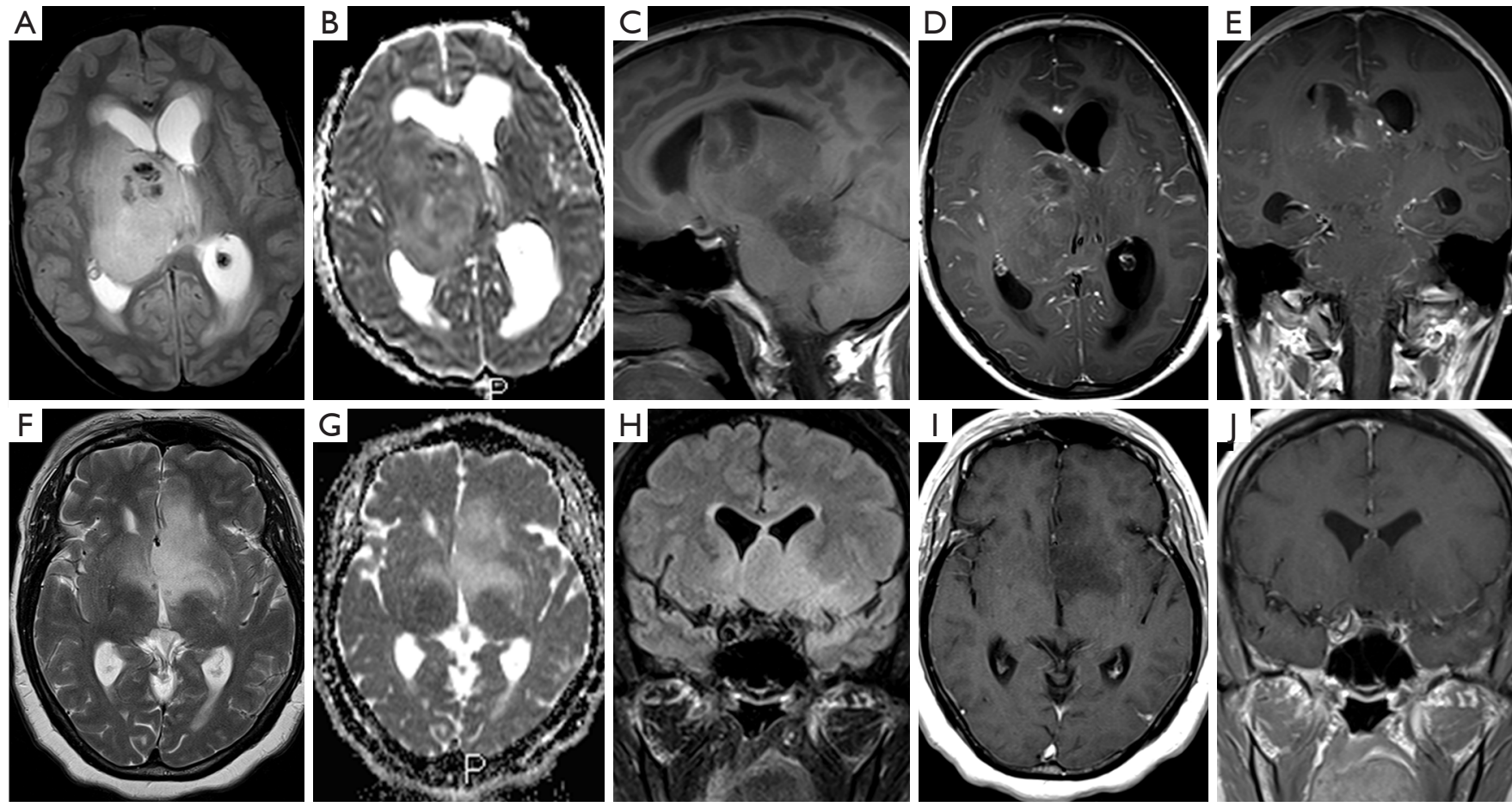

Figure 4 Variable morphology of H3 K27M-mutant diffuse midline glioma. Case 4: T2w (A), ADC map (B), T1w (C) and post Gadolinium T1w (D,E) images demonstrating a large, partially haemorrhagic tumour. Case 6: T2w (F), ADC map (G), FLAIR (H) and post gadolinium T1w $(\mathrm{I}, \mathrm{J})$ in a patient with a non-enhancing glioma. ADC, apparent diffusion coefficient.

glioblastoma types (36), which could give rise to the visual observation. On the contrary, indolent low grade gliomas typically show facilitated diffusion, evidenced by higher absolute ADC and ADC ratio values (27).

Chen et al. recently compared ADC ROI measurements in H3 K27M-mutant diffuse midline glioma $(\mathrm{n}=19)$ to a H3 K27M wild-type patient group (29). This study reported an average $\mathrm{ADC}_{\min }$ of $0.734( \pm 0.120 \mathrm{SD}) \times 10^{-3} \mathrm{~mm}^{2} / \mathrm{s}$ and an average $\mathrm{ADC}_{\min / \mathrm{NAWM}}$ ratio of $0.972( \pm 0.165) \times 10^{-3} \mathrm{~mm}^{2} / \mathrm{s}$. In our patient group, the results for $\mathrm{ADC}_{\min }$ [mean $\left.0.84( \pm 0.15) \times 10^{-3} \mathrm{~mm}^{2} / \mathrm{s}\right]$ and $\mathrm{ADC}_{\text {min/NAWM }}$ ratio $[1.097$ $\left.( \pm 0.149) \times 10^{-3} \mathrm{~mm}^{2} / \mathrm{s}\right]$ are slightly higher despite using a similar ROI method. Furthermore, the majority of $\mathrm{ADC}_{\min }$ [13/15 (87\%)] and $\mathrm{ADC}_{\min / \mathrm{NAWM}}$ ratio $[12 / 15(80 \%)]$ values in our research exceed the proposed $\mathrm{ADC}_{\min }$ threshold $\left(0.728 \times 10^{-3} \mathrm{~mm}^{2} / \mathrm{s}\right)$ and $\mathrm{ADC}_{\text {min/NAWM }}$ ratio threshold (0.982), respectively (29). This deviation may to some extent be explained by technical factors, such as differences in DWI acquisition and modelling. Observer dependence could also play a role, although excellent reproducibility has been demonstrated for region based glioma and NAWM ADC measurements in prior research $(27,37)$.
In our study, less variability (smaller SD) was shown for $\mathrm{ADC}_{\text {min }}$ compared to $\mathrm{ADC}_{\text {mean }}$ values, both for the use of the ROI based and the histogram technique. Given the high proportion of necrotic lesions, when using a ROI assessment the $\mathrm{ADC}_{\min }$ method (using several small ROIs) appears technically more feasible to assess diffusivity in midline gliomas. The placement of a single circular $\mathrm{ADC}_{\text {mean }} \mathrm{ROI}$ in tumours with large portions of necrosis or haemorrhage would invariably exclude parts of the lesion. All ( $\mathrm{n}=3)$ non-Gadolinium-enhancing, solid H3 K27Mmutant gliomas exhibited $\mathrm{ROI} \mathrm{ADC}_{\text {mean/NAWM }}$ ratio values in the range reported for non-enhancing glioblastoma (27), thus $\mathrm{ADC}_{\text {mean }}$ measurement could potentially be informative for such cases. The regional NAWM ADC values measured in our study showed the least variation (smallest SD) and were numerically in keeping with previous research in normal white matter (38).

The ROI parameters, specifically $\mathrm{ADC}_{\text {min }}$ and $\mathrm{ADC}_{\min } /$ NAWM ratio, appeared representative of the $5^{\text {th }}$ and $10^{\text {th }} \mathrm{ADC}$ histogram percentiles. Most tumour histograms showed positive kurtosis and skewness, corresponding to the visually perceived ADC heterogeneity. The clinical impact of 

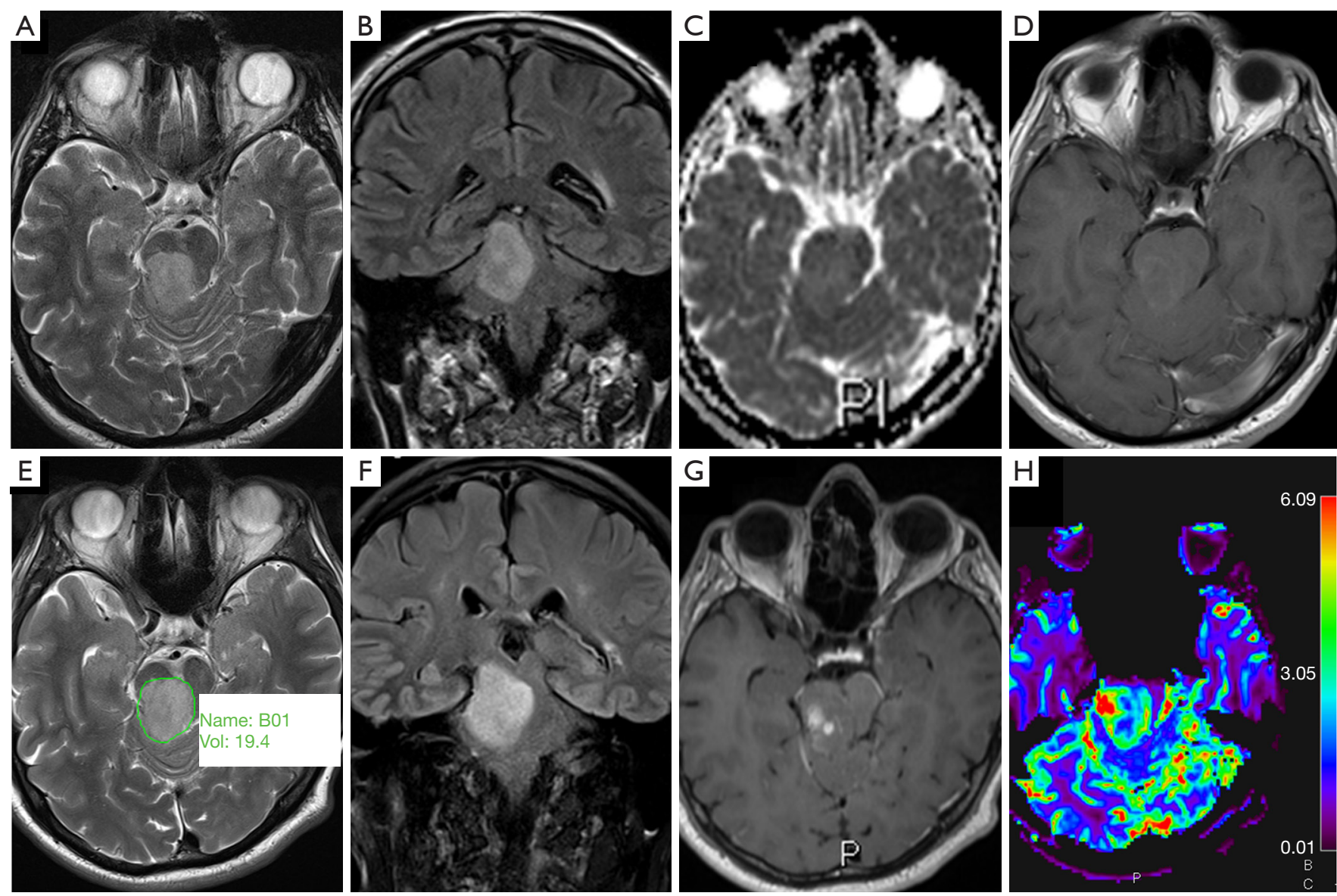

Figure 5 Serial progression and perfusion features of H3 K27M-mutant diffuse midline glioma. Case 7: T2w (A), FLAIR (B), ADC map (C) and post gadolinium T1w images (D) performed on admission showing a non-gadolinium enhancing tumour with ADC signal approximately isointense to surrounding brain. The same patient after 7 months: T2w (E, featuring volumetric segmentation example), FLAIR (F), post gadolinium T1w $(\mathrm{G})$ and DSC perfusion-derived rCBV map $(\mathrm{H})$ revealing interval progression with development of contrast enhancement and pathologically raised blood volume (arrow). ADC, apparent diffusion coefficient; DSC, dynamic susceptibility contrast enhanced perfusion MRI; rCBV, relative cerebral blood volume.

diffusion findings in H3 K27M-mutant glioma remains yet unknown; Aboian et al. recently compared ADC histogram statistics between paediatric H3 M27M-mutant and wildtype diffuse midline gliomas observing no difference (39). Conversely, Su et al. were recently able to predict H3 K27M glioma genotype using a FLAIR based machine learning algorithm (40) without considering DWI features.

Whilst our study did not include specific testing of ADC repeatability, recent evidence indicates that the majority of diffusion MRI derived parameters, and in particular ADC, are sufficiently robust across $1.5 \mathrm{~T}$ and $3 \mathrm{~T}$ scanners and suitable for multi-centre clinical studies (41). Furthermore, in the case of relative ADC measurements normalised to unaffected white matter $\left(\mathrm{ADC}_{\text {min/NAWM }}\right.$ ratio and $\mathrm{ADC}_{\text {mean } /}$
NAWM ratio), any potential effect from scanner variation would be minimised.

Variable T2/FLAIR characteristics, tumour border definition and contrast patterns were encountered, with solid and rim enhancement patterns coexisting. T2 hypointense glioma regions tended to correspond to low ADC signal in keeping with features previously reported for DIPG anaplastic components (42). Haemorrhage was evident in one third of cases, which has been hypothesised to represent a specific feature of H3 K27M-mutant gliomas in the cord (43). The diversity of glioma features and lesion volumes may reflect discovery at different time points during the disease, as suggested by the serial morphology change in case 7 . High genomic instability has been 

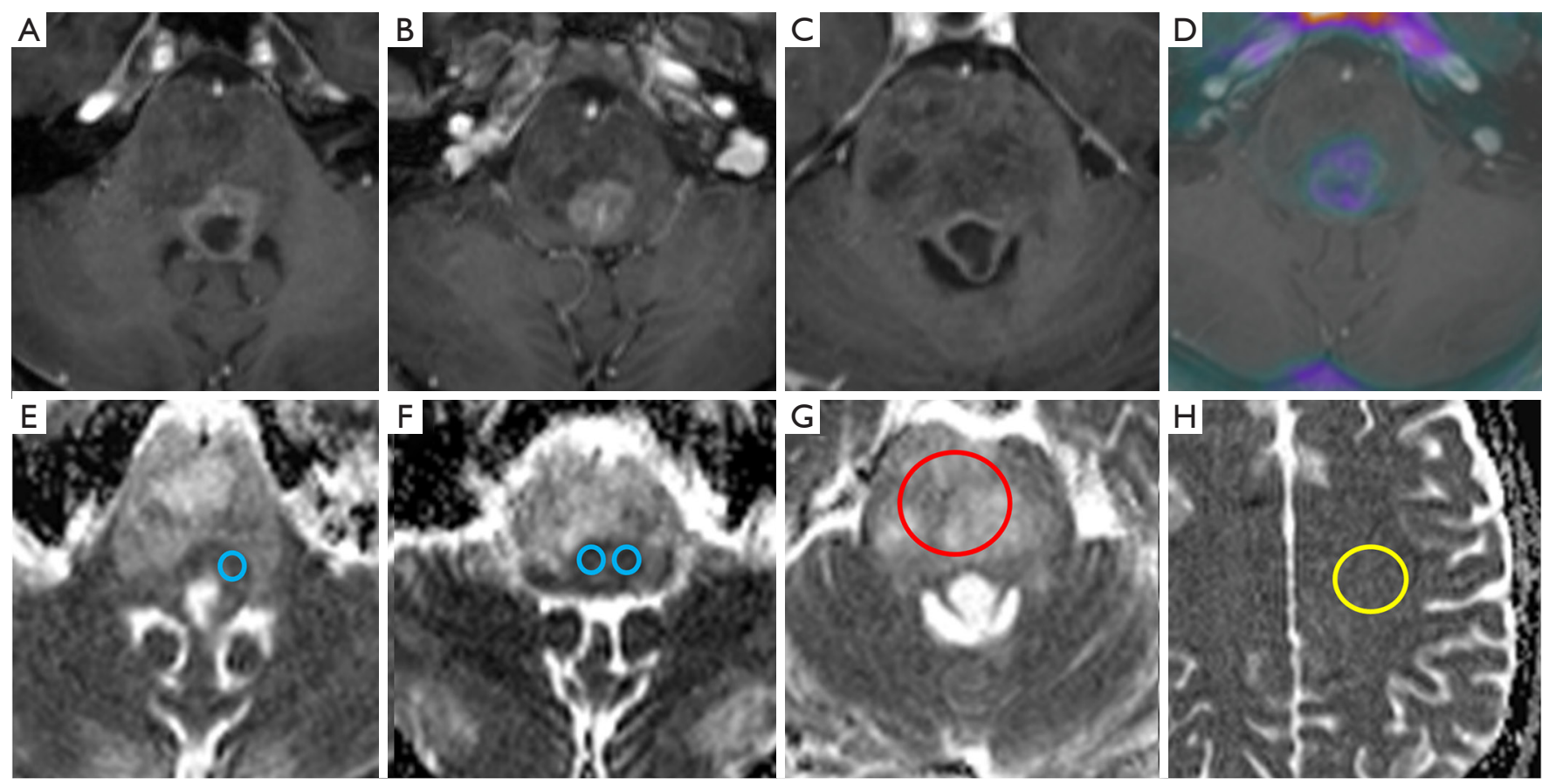

Figure 6 Quantitative ADC measurement in H3 K27M histone-mutant glioma. T2w (A,B), post gadolinium T1w (C) and T1w/18F choline PET fusion image (D) demonstrating a partially necrotic H3 K27M-mutant diffuse midline glioma (case 3) with considerable signal heterogeneity on all image sequences. $\mathrm{ADC}$ maps in the same patient featuring superimposed $\mathrm{ADC}_{\text {min }}(\mathrm{E}, \mathrm{F}), \mathrm{ADC}_{\text {mean }}(\mathrm{G})$ and $\mathrm{ADC} \mathrm{NawM}_{\mathrm{N}}(\mathrm{H})$ regions of interest $\left(\mathrm{ADC}_{\min }=\right.$ blue, $\mathrm{ADC}_{\text {mean }}=$ red, $\left.\mathrm{ADC}_{\mathrm{NAWM}}=\mathrm{yellow}\right) . \mathrm{ADC}$, apparent diffusion coefficient.

discovered in histone-mutant gliomas (7), which may be associated with complex lesion architecture and imaging changes over time.

As a limitation, this study did not perform a comparison to other midline glioma genotypes. The cohort is small due to the rarity of the disease and its recent [2016] classification, which limits the generalisability of our results. We minimized potential bias by working according to published, reproducible ROI ADC quantification methods whilst being blinded to published thresholds.

In summary, our analysis underscores the potential role of diffusion-weighted MRI as a biomarker of H3 K27Mmutant glioma. While low diffusivity appears to be a typical feature of this tumour type, we observed a broader spectrum of $\mathrm{ADC}_{\min }$ and $\mathrm{ADC}_{\min / \mathrm{NAWM}}$ ratio values than previously reported.

\section{Conclusions}

Heterogeneous morphology and diffusivity, commonly featuring moderately low ADC values in solid tumour, represents a quantifiable feature of $\mathrm{H} 3 \mathrm{~K} 27 \mathrm{M}$-mutant glioma. Regional ADC measurements appeared representative of volumetric histogram data in this study.

\section{Acknowledgments}

Funding: No specific grant funding is associated with the work presented. University College London/UCL Hospitals receive proportional funding from the National Institute for Health Research Biomedical Research Centre.

\section{Footnote}

Conflicts of Interest: All authors have completed the ICMJE uniform disclosure form (available at http://dx.doi. org/10.21037/qims-19-954). Dr. KM serves as an unpaid editorial board member of Quantitative Imaging in Medicine and Surgery. The other authors have no conflicts of interest to declare.

Ethical Statement: Institutional ethics approval was obtained, with informed consent waived due to the nature of the disease and retrospective analysis. 
Open Access Statement: This is an Open Access article distributed in accordance with the Creative Commons Attribution-NonCommercial-NoDerivs 4.0 International License (CC BY-NC-ND 4.0), which permits the noncommercial replication and distribution of the article with the strict proviso that no changes or edits are made and the original work is properly cited (including links to both the formal publication through the relevant DOI and the license). See: https://creativecommons.org/licenses/by-nc-nd/4.0/.

\section{References}

1. Donaldson SS, Laningham F, Fisher PG. Advances toward an understanding of brainstem gliomas. J Clin Oncol 2006;24:1266-72.

2. Wu G, Broniscer A, McEachron TA, Lu C, Paugh BS, Becksfort J, Qu C, Ding L, Huether R, Parker M, Zhang J, Gajjar A, Dyer MA, Mullighan CG, Gilbertson RJ, Mardis ER, Wilson RK, Downing JR, Ellison DW, Zhang, J, Baker SJ. Somatic histone $\mathrm{H} 3$ alterations in pediatric diffuse intrinsic pontine gliomas and non-brainstem glioblastomas. Nat Genet 2012;44:251-3.

3. Sturm D, Witt H, Hovestadt V, Khuong-Quang DA, Jones DTW, Konermann C, Pfaff E, Tönjes M, Sill M, Bender S, Kool M, Zapatka M, Becker N, Zucknick M, Hielscher T, Liu XY, Fontebasso AM, Ryzhova M, Albrecht S, Jacob K, Wolter M, Ebinger M, Schuhmann MU, van Meter T, Frühwald MC, Hauch H, Pekrun A, Radlwimmer B, Niehues T, von Komorowiski G, Dürken M, Kulozik AE, Madden J, Donson A, Foreman NK, Drissi R, Fouladi M, Scheurlen W, von Deimling A, Monoranu C, Roggendorf W, Herold-Mende C, Unterberg A, Kramm CM, Felsberg J, Hartmann C, Wiestler B, Wick W, Milde T, Witt O, Lindroth AM, Schwartzentruber J, Faury D, Fleming A, Zakrzewska M, Liberski PP, Zakrzewski K, Hauser P, Garami M, Klekner A, Bognar L, Morrisy S, Cavalli F, Taylor MD, van Sluis P, Koster J, Versteeg R, Volckmann R, Mikkelsen T, Aldape K, Reifenberger G, Collins VP, Majewski J, Korshunov A, Lichter P, Plass C, Jabado N, Pfister S. Hotspot Mutations in H3F3A and IDH1 Define Distinct Epigenetic and Biological Subgroups of Glioblastoma. Cancer Cell 2012;22:425-37.

4. Gilbert AR, Zaky W, Gokden M, Fuller CE, Ocal E, Leeds NE, Fuller GN. Extending the Neuroanatomic Territory of Diffuse Midline Glioma, K27M Mutant: Pineal Region Origin. Pediatr Neurosurg 2018;53:59-63.

5. Louis DN, Ohgaki H, Wiestler OD, Cavenee WK, Burger PC, Jouvet A, Scheithauer BW, Kleihues P. The 2007
WHO Classification of Tumours of the Central Nervous System. Acta Neuropathol (Berl) 2007;114:97-109.

6. Schwartzentruber J, Korshunov A, Liu XY, Jones DTW, Pfaff E, Jacob K, Sturm D, Fontebasso AM, Khuong Quang DA, Tönjes M, Hovestadt V, Albrecht S, Kool M, Nantel A, Konermann C, Lindroth A, Jäger N, Rausch T, Ryzhova M, Korbel JO, Hielscher T, Hauser P, Garami M, Klekner A, Bognar L, Ebinger M, Schuhmann MU, Scheurlen W, Pekrun A, Frühwald MC, Roggendorf W, Kramm C, Dürken M, Atkinson J, Lepage P, Montpetit A, Zakrzewska M, Zakrzewski K, Liberski P, Dong Z, Siegel P, Kulozik AE, Zapatka M, Guha A, Malkin D, Felsberg J, Reifenberger G, von Deimling A, Ichimura K, Collins VP, Witt H, Milde T, Witt O, Zhang C, Castelo-Branco P, Lichter P, Faury D, Tabori U, Plass C, Majewski J, Pfister S, Jabado N. Driver mutations in histone H3.3 and chromatin remodelling genes in paediatric glioblastoma. Nature 2012;482:226-31.

7. Fontebasso AM, Papillon-Cavanagh S, Schwartzentruber J, Nikbakht H, Gerges N, Fiset PO, Bechet D, Faury D, De Jay N, Ramkisson LA, Corcoran A, Jones DTW, Surm D, Johann P, Tomita T, Goldman S, Nagib M, Bendel A, Goumnerova L, Bowers DC, Leonard JR, Rubin JB, Alden T, Browd S, Geyer JR, Leary S, Jallo G, Cohen K, Gupta N, Prados MD, Carret AS, Ellezam B, Crevier L, Klekner A, Bognar L, Hauser P, Garami M, Myseros J, Dong Z, Siegel PM, Malkin H, Ligon AH, Albrecht S, Pfister SM, Ligon KL, Majewski J, Jabado N, Kieran MW. Recurrent somatic mutations in ACVR1 in pediatric midline highgrade astrocytoma. Nat Genet 2014;46:462-6.

8. Khuong-Quang DA, Buczkowicz P, Rakopoulos P, Liu XY, Fontebasso AM, Bouffet E, Bartels U, Albrecht S, Schwartzentruber J, Letourneau L, Bourgey M, Bourque G, Montpetit A, Bourret G, Lepage P, Fleming A, Lichter P, Kool M, von Deimling A, Sturm D, Korshunov A, Faury D, Jones DT, Majewski J, Pfister SM, Jabado N, Hawkins C. K27M mutation in histone $\mathrm{H} 3.3$ defines clinically and biologically distinct subgroups of pediatric diffuse intrinsic pontine gliomas. Acta Neuropathol (Berl) 2012;124:439-47.

9. Kleinschmidt-DeMasters BK, Mulcahy Levy JM. H3 K27M-mutant gliomas in adults vs. children share similar histological features and adverse prognosis. Clin Neuropathol 2018;37:53-63.

10. Meyronet D, Esteban-Mader M, Bonnet C, Joly MO, Uro-Coste E, Amiel-Benouaich A, Forest F, RousselotDenis C, Burel-Vandenbos F, Bourg V, Guyotat J, Fenouil T, Jouvet A, Honnorat J, Ducray F. Characteristics of 
H3 K27M-mutant gliomas in adults. Neuro Oncol 2017;19:1127-34.

11. Schreck KC, Ranjan S, Skorupan N, Bettegowda C, Eberhart CG, Ames HM, Holdhoff M. Incidence and clinicopathologic features of H3 K27M mutations in adults with radiographically-determined midline gliomas. J Neurooncol 2019;143:87-93.

12. Lee J, Solomon DA, Tihan T. The role of histone modifications and telomere alterations in the pathogenesis of diffuse gliomas in adults and children. J Neurooncol 2017;132:1-11.

13. Venneti S, Garimella MT, Sullivan LM, Martinez D, Huse JT, Heguy A, Santi M, Thompson CB, Judkins AR. Evaluation of histone 3 lysine 27 trimethylation (H3K27me3) and enhancer of Zest 2 (EZH2) in pediatric glial and glioneuronal tumors shows decreased H3K27me3 in H3F3A K27M mutant glioblastomas. Brain Pathol 2013;23:558-64.

14. Brandner S, von Deimling A. Diagnostic, prognostic and predictive relevance of molecular markers in gliomas: Molecular markers in gliomas. Neuropathol Appl Neurobiol 2015;41:694-720.

15. Louis DN, Perry A, Reifenberger G, von Deimling A, Figarella-Branger D, Cavenee WK, Ohgaki H, Wiestler OD, Kleihues P, Ellison DW. The 2016 World Health Organization Classification of Tumors of the Central Nervous System: a summary. Acta Neuropathol (Berl) 2016;131:803-20.

16. Fukami S, Nakajima N, Okada H, Akimoto J, Miki T, Fukuhara H, Shishido-Hara Y, Nagao T, Tsuda M, Kohno M. Pathological findings and clinical course of midline paraventricular gliomas diagnosed using a neuroendoscope. World Neurosurg 2018;114:e366-e377.

17. Daoud EV, Rajaram V, Cai C, Oberle RJ, Martin GR, Raisanen JM, White CL 3rd, Foong C, Mickey BE, Pan E, Hatanpaa KJ. Adult Brainstem Gliomas With H3K27M Mutation: Radiology, Pathology, and Prognosis. J Neuropathol Exp Neurol 2018;77:302-11.

18. Aboian MS, Solomon DA, Felton E, Mabray MC, Villanueva-Meyer JE, Mueller S, Cha S. Imaging Characteristics of Pediatric Diffuse Midline Gliomas with Histone H3 K27M Mutation. AJNR Am J Neuroradiol 2017;38:795-800.

19. Gupta A, Young RJ, Karimi S, Sood S, Zhang Z, Mo Q, Gutin PH, Holodny AI, Lassman AB. Isolated diffusion restriction precedes the development of enhancing tumor in a subset of patients with glioblastoma. AJNR Am J Neuroradiol 2011;32:1301-6.
20. Lober RM, Cho YJ, Tang Y, Barnes PD, Edwards MS, Vogel H, Fisher PG, Monje M, Yeom KW. Diffusionweighted MRI derived apparent diffusion coefficient identifies prognostically distinct subgroups of pediatric diffuse intrinsic pontine glioma. J Neurooncol 2014;117:175-82.

21. Capper D, Preusser M, Habel A, Sahm F, Ackermann U, Schindler G, Pusch S, Mechtersheimer G, Zentgraf H, von Deimling A. Assessment of BRAF V600E mutation status by immunohistochemistry with a mutationspecific monoclonal antibody. Acta Neuropathol (Berl) 2011;122:11-9.

22. Castel D, Philippe C, Calmon R, Le Dret L, Truffaux N, Boddaert N, Pages M, Taylor KR, Saulnier P, Lacroix L, Mackay A, Jones C, Sainte-Rose C, Blauwblomme T, Andreiuolo F, Puget S, Grill J, Varlet P, Debily MA. Histone H3F3A and HIST1H3B K27M mutations define two subgroups of diffuse intrinsic pontine gliomas with different prognosis and phenotypes. Acta Neuropathol (Berl) 2015;130:815-27.

23. Reuss DE, Sahm F, Schrimpf D, Wiestler B, Capper D, Koelsche C, Schweizer L, Korshunov A, Jones DTW, Hovestadt V, Mittelbronn M, Schittenhelm J, HeroldMende C, Unterberg A, Platten M, Weller M, Wick W, Pfister SM, von Deimling A. ATRX and IDH1$\mathrm{R} 132 \mathrm{H}$ immunohistochemistry with subsequent copy number analysis and IDH sequencing as a basis for an 'integrated' diagnostic approach for adult astrocytoma, oligodendroglioma and glioblastoma. Acta Neuropathol (Berl) 2015;129:133-46.

24. Jaunmuktane Z, Capper D, Jones DTW, Schrimpf D, Sill M, Dutt M, Suraweera N, Pfister SM, von Deimling A, Brandner S. Methylation array profiling of adult brain tumours: diagnostic outcomes in a large, single centre. Acta Neuropathol Commun 2019;7:24.

25. Park MY, Byun JY. Understanding the mathematics involved in calculating apparent diffusion coefficient maps. AJR Am J Roentgenol 2012;199:W784.

26. Ramaglia A, Tortora D, Mankad K, Lequin M, Severino M, D’Arco F, Löbel U, Benenati M, de Leng WJW, de Marco P, Milanaccio C, Rossi A, Morana G. Role of diffusion weighted imaging for differentiating cerebral pilocytic astrocytoma and ganglioglioma BRAF V600E-mutant from wild type. Neuroradiology 2020;62:71-80.

27. Thust SC, Hassanein S, Bisdas S, Rees JH, Hyare H, Maynard JA, Brandner S, Tur C, Jäger HR, Yousry TA, Mancini L. Apparent diffusion coefficient for molecular subtyping of non-gadolinium-enhancing WHO grade 
II/III glioma: volumetric segmentation versus twodimensional region of interest analysis. Eur Radiol 2018;28:3779-88.

28. Xing Z, Yang X, She D, Lin Y, Zhang Y, Cao D. Noninvasive Assessment of IDH Mutational Status in World Health Organization Grade II and III Astrocytomas Using DWI and DSC-PWI Combined with Conventional MR Imaging. AJNR Am J Neuroradiol 2017;38:1138-44.

29. Chen H, Hu W, He H, Yang Y, Wen G, Lv X. Noninvasive assessment of $\mathrm{H} 3 \mathrm{~K} 27 \mathrm{M}$ mutational status in diffuse midline gliomas by using apparent diffusion coefficient measurements. Eur J Radiol 2019;114:152-9.

30. Qiu T, Chanchotisatien A, Qin Z, Wu J, Du Z, Zhang X, Gong F, Yao Z, Chu S. Imaging characteristics of adult H3 K27M-mutant gliomas. J Neurosurg 2019;1:1-9.

31. Patterson DM, Padhani AR, Collins DJ. Technology insight: water diffusion MRI--a potential new biomarker of response to cancer therapy. Nat Clin Pract Oncol 2008;5:220-33.

32. Yan R, Haopeng P, Xiaoyuan F, Jinsong W, Jiawen Z, Chengjun Y, Tianming Q, Ji X, Mao S, Yueyue D, Yong Z, Jianfeng L, Zhenwei Y. Non-Gaussian diffusion MR imaging of glioma: comparisons of multiple diffusion parameters and correlation with histologic grade and MIB1 (Ki-67 labeling) index. Neuroradiology 2016;58:121-32.

33. Leu K, Ott GA, Lai A, Nghiemphu PL, Pope WB, Yong WH, Liau LM, Cloughesy TF, Ellingson BM. Perfusion and Diffusion MRI Signatures in Histologic and Genetic Subtypes of WHO Grade II-III Diffuse Gliomas. J Neurooncol 2017;134:177-88.

34. Yamashita K, Hiwatashi A, Togao O, Kikuchi K, Hatae R, Yoshimoto K, Mizoguchi M, Suzuki SO, Yoshiura T, Honda H. MR Imaging-Based Analysis of Glioblastoma Multiforme: Estimation of IDH1 Mutation Status. AJNR Am J Neuroradiol 2016;37:58-65.

35. Hilario A, Ramos A, Perez-Nuñez A, Salvador E, Millan JM, Lagares A, Sepulveda JM, Gonzalez-Leon P, Hernandez-Lain A, Ricoy JR. The Added Value of Apparent Diffusion Coefficient to Cerebral Blood Volume in the Preoperative Grading of Diffuse Gliomas. Am J Neuroradiol 2012;33:701-7.

36. Neumann JE, Dorostkar MM, Korshunov A, Mawrin C, Koch A, Giese A, Schüller U. Distinct Histomorphology in Molecular Subgroups of Glioblastomas in Young Patients. J Neuropathol Exp Neurol 2016;75:408-14.

37. Maynard J, Okuchi S, Wastling S, Busaidi AA, Almossawi O, Mbatha W, Brandner S, Jaunmuktane Z, Koc AM,
Mancini L, Jäger R, Thust S. World Health Organization Grade II/III Glioma Molecular Status: Prediction by MRI Morphologic Features and Apparent Diffusion Coefficient. Radiology 2020;296:111-21.

38. Hakulinen U, Brander A, Ryymin P, Öhman J, Soimakallio S, Helminen M, Dastidar P, Eskola H. Repeatability and variation of region-of-interest methods using quantitative diffusion tensor MR imaging of the brain. BMC Med Imaging 2012;12:30.

39. Aboian MS, Tong E, Solomon DA, Kline C, Gautam A, Vardapetyan A, Tamrazi B, Li Y, Jordan CD, Felton E, Weinberg B, Braunstein S, Mueller S, Cha S. Characteristics of Pediatric Diffuse Midline Gliomas with Histone H3-K27M Mutation Using Apparent Diffusion Coefficient Histogram Analysis. Am J Neuroradiol 2019;40:1804-10.

40. Su X, Chen N, Sun H, Liu Y, Yang X, Wang W, Zhang S, Tan Q, Su J, Gong Q, Yue Q. Automated Machine Learning Based on Radiomics Features Predicts H3 K27M Mutation in Midline Gliomas of the Brain. Neuro Oncol 2020;22:393-401.

41. Grech-Sollars M, Hales PW, Miyazaki K, Raschke F, Rodriguez D, Wilson M, Gill SK, Banks T, Saunders DE, Clayden JD, Gwilliam MN, Barrick TR, Morgan PS, Davies NP, Rositter J, Auer DP, Grundy R, Leach MO, Howe FA, Peet AC, Clark CA. Multi-centre reproducibility of diffusion MRI parameters for clinical sequences in the brain. Nmr Biomed 2015;28:468-85.

42. Löbel U, Sedlacik J, Reddick WE, Kocak M, Ji Q, Broniscer A, Hillenbrand CM, Patay Z. Quantitative Diffusion Weighted Imaging and Dynamic Susceptibilityweighted Contrast-enhanced Perfusion MRI Analysis of T2-hypointense Lesion Components in Pediatric Diffuse Intrinsic Pontine Glioma. AJNR Am J Neuroradiol 2011;32:315-22.

43. Jung JS, Choi YS, Ahn SS, Yi S, Kim SH, Lee SK. Differentiation between spinal cord diffuse midline glioma with histone H3 K27M mutation and wild type: comparative magnetic resonance imaging. Neuroradiology 2019;61:313-22.

Cite this article as: Thust S, Micallef C, Okuchi S, Brandner S, Kumar A, Mankad K, Wastling S, Mancini L, Jäger HR, Shankar A. Imaging characteristics of H3 K27M histonemutant diffuse midline glioma in teenagers and adults. Quant Imaging Med Surg 2021;11(1):43-56. doi: 10.21037/qims-19-954 